\title{
MECHANICAL BEHAVIORS OF SIDE-PLATE JOINT BETWEEN WALLED CONCRETE-FILLED STEEL TUBULAR COLUMN AND H-SHAPED STEEL BEAM
}

\author{
Yu-Qi Huang ${ }^{1,}{ }^{*}$, Ji-Ping Hao ${ }^{1}$, Rui Bai ${ }^{2}$, Chun-Lei Fan ${ }^{1}$ and Qiang Xue ${ }^{1}$ \\ ${ }^{1}$ School of Civil Engineering, Xi'an University of Architecture \& Technology, Xi'an, China \\ ${ }^{2}$ Department of Civil and Environmental Engineering, The Hong Kong Polytechnic University, Hong Kong, China \\ *(Corresponding author: E-mail: huangyuqi 1989@,163.com)
}

\section{A B S T RA C T}

The mechanical behaviors of an innovative joint, the side-plate joint, that connects a walled concrete-filled steel tubular column and an $\mathrm{H}$-shaped steel beam, were analytically and experimentally investigated. The mechanical characteristics of the joint panel zone under shear were studied. A three-stage shear-yield model was established for describing the relation between shear force and shear deformation of the joint panel zone. Three failure modes and the corresponding evaluating criteria were proposed for design practices based on the shear-yield model and internal force transfer mechanism. To verify the reliability of the proposed method, three full-scale walled concrete-filled steel tubular column joints were tested under cyclic loads. Moreover, the hysteresis curve, skeleton curve, ductility, energy dissipation capacity, stiffness degradation, and strain of the joint were evaluated based on the experimental results. The predicted failure mode and ultimate bearing capacity predicted by the proposed method show good agreement with the test results; the hysteresis loop of the specimen is relatively full and shuttle-shaped without discernible pinching, which indicates the side-plate joint exhibits preferable deformation performance and possesses an energy dissipation capacity.

\section{AR T I C LE H I S T O RY}

$\begin{array}{ll}\text { Received: } & 28 \text { February } 2020 \\ \text { Revised: } & 25 \text { August } 2020 \\ \text { Accepted: } & \quad 10 \text { September } 2020\end{array}$

\section{K E Y W O R D S}

Walled concrete-filled steel tubular column;

Side-plate joint

Panel zone;

Failure mode;

Full-scale specimen

Hysteresis behavior

\section{Introduction}

A concrete-filled steel tube (CFST) column is the vertical bearing member formed by pouring core concrete into a steel tube. Core concrete can increase the stiffness and vertical bearing capacity of the column and restrain the local buckling of the steel tube. The external hollow steel tube in turn can be used as the pouring formwork of the core concrete, and it can provide constraints on the core concrete, thereby keeping the concrete in a three-way compression state and improving its tensile and compressive strengths. CFST columns are widely used in construction engineering owing to their characteristics such as large bearing capacity and stiffness, excellent economy, and ease of processing and construction [1-3].

Typically, CFST columns and beams are combined to form a reliable steel moment frame system. The beam-to-column joints are the key segments for transmitting forces. The design of the joints is an important part of structural design. Research on the failure mode and mechanical performance of the joints is a prerequisite to ensure the normal operation of a structure. In engineering applications, the CFST columns are commonly shaped as circular and rectangular sections. According to the Technical Code for Concrete-Filled Steel Tubular Structures (GB 50936-2014) [4], internal diaphragm and outer reinforced-ring-plate are recommended for use in the joints between CFST columns and steel beams.

To ensure that the core concrete in the internal diaphragm joint is poured smoothly, the diameter of a pouring hole, which is not less than 200 $\mathrm{mm}$, must be opened in the internal diaphragm. If the column section is too small to meet the pouring requirements, the outer reinforced-ring-plate joint can be adopted. An internal diaphragm does not exist in the outer reinforced-ring-plate joint, and the beam flange axial force is transmitted through the ring plate. The width of the plate should not be less than 0.7 times the flange width of the steel beam [4]. In engineering practices, the column width may be the same as the thickness of the infill wall to avoid column exposure inside the room and increase the usable space, which leads to a small column section. Therefore, the internal diaphragm joint cannot be adopted in such CFST columns. Similarly, the outer ring plate joint, which has a wider boundary, protrudes from the beam-column members and affects the architectural beauty and decoration layout, and should be avoided in engineering applications as well.

To avoid the exposure of columns inside a room, Hao et al. [5, 6] proposed a walled concrete-filled steel tube (WCFT) column with a large aspect ratio and thickness equal to that of the infilled wall in multi-story steel structure buildings. Fig. 1 shows a typical section of a WCFT column. Due to the small width of this column, the internal diaphragm joint cannot be used, and the outer-ring-plate joint could possibly influence the indoor beauty and practicality. Therefore, the authors propose a new type of side-plate joint suitable for a WCFT column. Based on the components of the side-plate joint, this paper presents a theoretical study on the force-transfer mechanism and failure mode at the panel zone and beam end. Quasi-static tests of three full-scale joint specimens were used to verify the theoretical research, and demonstrate the hysteretic performance, failure mode, deformation capacity, and bearing capacity of the side-plate joint. The work offers guidance for the mechanical property analysis and design of the side-plate joint.

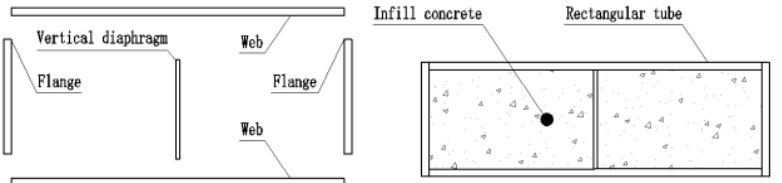

Fig. 1 Walled concrete-filled steel tubular (WCFT) column

\section{Theoretical analysis}

The components of the side-plate joint in this study are shown in Fig. 2. The embedded side plate is set along the web of the WCFT column. The cantilever segment of the side plate extend outward along the steel beam aims to transmit the bending moment at the beam end to the joint panel directly. The height of the extended part can be determined according the moment. Details of the joint configuration can be found in sections 2.1 to 2.3. The end of the beam is welded to the WCFT column flange. The moment at the beam end is mainly transmitted through the side plate and column flange, and the shear force is transmitted through the weld between the beam web and column flange.

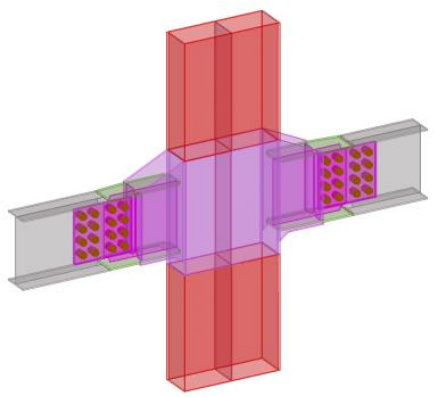

(a) Integrated schematic view of side-plate joint 


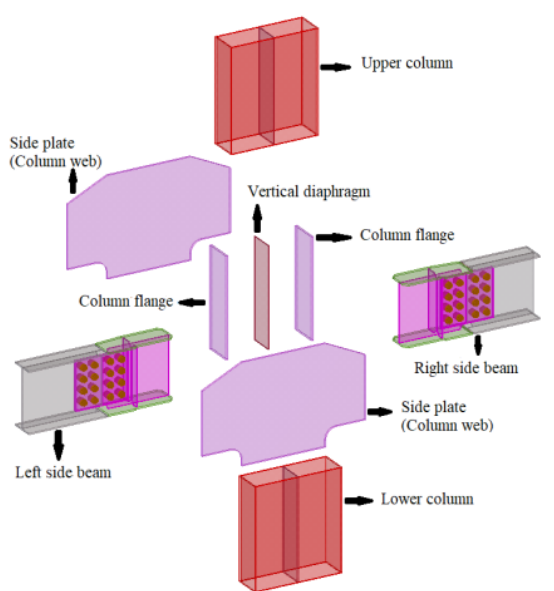

(b) Exploded schematic view of side-plate joint

Fig. 2 Typical side-plate joint of a WCFT column-H-shaped beam

\subsection{Shear mechanism of the joint panel zone}

The design of panel zone of the beam-column joint is a critical part in the seismic design process, where a reasonable force-transmission mechanism describing the performance of the joint panel zone under horizontal earthquakes must be established. Fig. 3 shows the bending moment distribution at the column and beam ends of the frame and the stress on the joint under horizontal seismic forces. The moments at the beam ends on both sides of the intermediate column are anti-symmetric. If the moment at the end of the steel beam reaches the full-section plastic moment $M_{b p}$, the pair of force couples that decomposes in the panel zone is defined as follows:

$T=C=M_{b p} /\left(h_{b}-t_{b f}\right)$

where $T$ and $C$ respectively represent the tension and pressure after the beam end moment is decomposed, $h_{b}$ is the height of the steel beam, and $t_{b f}$ is the thickness of the beam flange.

The beam-column joint panel zone in the middle floor of the frame system is considered as a part of the column. The position of the inflection point of the column is assumed to be located at the half story. As shown in Fig. $3 \mathrm{~b}$, the force couple $T / C$ that is decomposed from the beam moment causes a sudden change in the shear force at the panel zone. According to the moment balance, the column shear force can be obtained as follows:

$$
V_{c}=2 M_{b p} / H
$$

where $V_{c}$ is the shear force at the inflection point of the column, and $H$ is the distance between the upper and lower inflection points, i.e., the story height.

The shear force at the panel zone $\left(V_{n}\right)$ is calculated as

$V_{n}=\frac{2 M_{b p}}{h_{b}-t_{b f}}-\frac{2 M_{b p}}{H}=\frac{2 M_{b p}}{H} \times \frac{H-\left(h_{b}-t_{b f}\right)}{h_{b}-t_{b f}}$

$\frac{V_{n}}{V_{c}}=\frac{H-\left(h_{b}-t_{b f}\right)}{h_{b}-t_{b f}}$

Assuming that the heights of the steel beam and story are 0.4 to $0.6 \mathrm{~m}$ and 3 to $3.6 \mathrm{~m}$, respectively, the horizontal shear force $V_{n}$ at the joint panel zone is 4 to 8 times the shear force, $V_{c}$.



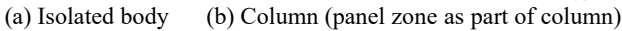

Fig. 3 Internal force analysis of joint under horizontal seismic effect

Considering the abrupt change in the shear force of the joint panel zone, the analysis of its shear bearing capacity is a prerequisite to satisfy the requirement of strong joints and weak members. Many scholars have theoretically analyzed and experimentally demonstrated the shear capacity of conventional CFST column joints [7-11]. Most researchers analyzed the shear contribution of each part based on the stress and deformation mechanisms, and then used the principle of superposition to obtain the total shear capacity of the joint panel zone [12]. The stress and deformation mechanisms of the core concrete adopt the "inclined beam-truss mechanism" proposed by Park and Paulay [13, 14] for concrete beam-column joints. For the side-slab joints of the WCFT column examined in this study, an internal diaphragm was not set in the joints, and thus the concrete in the panel zone will not show the shear mechanism of an inclined beam-truss. There are two ways for the axial force of the beam flange in the side-plate joint to be transmitted to the panel zone. First, the force is directly transmitted to the column web through the weld of the side-plate extension and beam flange. The force is also transmitted to the column flange through the weld between the beam flange and column flange.

Based on the mechanical characteristics of the side-plate joint of the WCFT column, the shear force development of the joint panel zone can be divided into the following three stages and is plotted in Fig. 4:

First stage: The end of the steel beam begins to bend, and the moment at the beam end is transmitted to the column web and column flange through the two above-mentioned paths. Owing to the bond stress between the column web and core concrete $[15,16]$, the core concrete and column web deform compatibly before reaching their ultimate bond strength. At this stage, the column web is subjected to shear deformation, the column flange is under bending, and the bond stress causes continuous strain to the column web and core concrete. The core concrete in turn provides shear capacity in the plane shear mode with large shear stiffness.

Second stage: As the bending moment at the beam end gradually increases, the bond stress between the core concrete and column web reaches a critical value or the stress on the core concrete reaches the ultimate shear strength (point A); the core concrete cannot further sustain the shear force. The column web and flange contribute the shear resistance of the joint panel zone, and with the moment increase, the column web yields (point B). At this stage, the shear stiffness of the panel zone comprises the shear stiffness of the column web and the bending stiffness of the column flange. Compared with that in the first stage, the shear stiffness is significantly reduced.

Third stage: After shear yielding at the column web (point B), the column flange contributes toward shear resistance due to bending deformation until the column flange side enters the yield state (point $\mathrm{C}$ ), at which point the joint panel zone also reaches the yield state. In this stage, research has shown that the strain on the column web does not increase sharply [17], indicating that the core concrete can effectively restrain the buckling of the column web.

The three stages representing the shear mechanism of the WCFT column joint panel zone are shown in Fig. 4. The corresponding shear force and deformation of turning points (A, B, and $\mathrm{C}$ ) must be determined to describe the shear performance of the panel zone. 


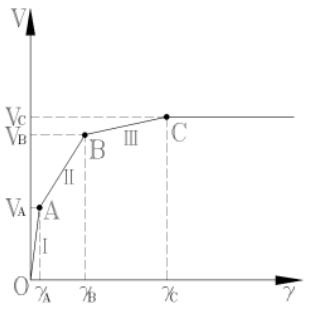

Fig. 4 Shear force-shear deformation model for side-plate joint panel

\subsection{Shear force-shear deformation model for panel zone}

As described in Section 2.1, the column web, column flange, and core concrete contribute to the shear resistance of the joint panel zone. The shear stiffness and bearing capacity of the core area of the node can be obtained by the superposition principle [12]. The axial force transmitted from the beam flange generates a shear force on the panel zone, resulting in shear deformation at the column web and bending deformation at the column flange, as shown in Fig. 5.

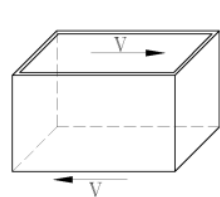

(a) Panel zone

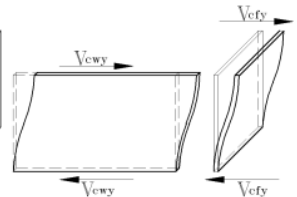

(b) Web (c) Flange
Fig. 5 Schematic of the deformation of steel tube at the panel zone

The shear stiffness of the column flange $\left(K_{c f}\right)$ due to the bending deformation is formulated as

$K_{c f}=2 \times \frac{3 E_{s} I_{c f} \times 2^{2}}{\left(h_{b}-t_{b f}\right)^{2}}=\frac{2 E_{s}\left(b_{c f}-2 t_{c w}\right) t_{c f}^{3}}{\left(h_{b}-t_{b f}\right)^{2}}$

where $E_{s}$ is the elastic modulus of steel, $I_{c f}$ is the bending stiffness of the column flange, $h_{b}$ is the height of the steel beam, $t_{b f}$ is the thickness of the steel beam flange, $b_{c f}$ is the width of the column flange, $t_{c w}$ is the thickness of column web in the joint panel zone, and $t_{c f}$ is the thickness of column flange in the joint panel zone.

The shear stiffness of the column web $\left(K_{c w}\right)$ due to shear deformation is formulated as

$K_{c w}=2 G_{s} A_{c w}=2 G_{s} h_{c w} t_{c w}$

where $G_{s}$ is the shear modulus of steel, $A_{c w}$ is the area of the single web side of the panel zone, and $h_{c w}$ is the section height on the side of column web.

The core concrete of the panel zone is subject to plane shear stress, and its shear stiffness $\left(K_{c c}\right)$ is formulated as

$K_{c c}=G_{c} A_{c c}=G_{c}\left(h_{c w}-2 t_{c f}\right)\left(b_{c f}-2 t_{c w}\right)$

where $G_{c}$ is the shear modulus of the core concrete and $A_{c c}$ is the area of the core concrete. As the thickness of the vertical diaphragm in the joint is very thin, its influence on the stiffness and shear capacity is ignored.

Equations (5) to (7) show the shear-stiffness contribution by each part of the joint. To determine the positions of the three turning points in Fig. 4, the shear force of these points must be determined.

First, the yield shear force of the column flange $\left(V_{c f y}\right)$ can be calculated by the principle of virtual work:

$V_{c f y}=\frac{4 M_{c f y}}{h_{b}-t_{b f}}=\frac{2 f_{y}\left(b_{c f}-2 t_{c w}\right) t_{c f}^{2}}{3\left(h_{b}-t_{b f}\right)}$

where $M_{c f y}$ is the yield moment at the column flange in the joint panel zone and $f_{y}$ is the yield strength of the steel. The shear deformation value in the panel zone is generally small, and the influence of the axial force on yield shear force $V_{c f y}$ is ignored.

It is assumed that the longitudinal strains of the steel tube and infill concrete in the joint panel zone are continuous under the axial force, and the axial stress $\sigma_{s N}$ of the steel tube is defined as

$$
\begin{aligned}
\sigma_{s N} & =\frac{N_{c} E_{s}}{E_{s} A_{c s}+E_{c} A_{c c}} \\
\sigma_{s N} & =\frac{N_{c} E_{s}}{E_{s}\left[2 h_{c w} t_{c w}+2 t_{c f}\left(b_{c w}-2 t_{c f}\right)\right]+E_{c}\left(h_{c w}-2 t_{c f}\right)\left(b_{c f}-2 t_{c w}\right)}
\end{aligned}
$$

where $N_{c}$ is the column's axial force, $E_{c}$ is the elastic modulus of the infill concrete, and $A_{c s}$ is the area of the steel tube that lies inside the panel zone.

According to the Von Mises yield criterion, when the column web in the panel zone is subjected to simultaneous shear and compression, the shear yield stress $\tau_{c w y}$ is formulated as

$$
\tau_{c w y}=\sqrt{f_{y}^{2}-\sigma_{s N}^{2}} / \sqrt{3}
$$

The shear stress in the joint panel zone is assumed to be uniformly distributed along the web side of the column, and therefore the shear yield force $V_{c w y}$ of the column web in the joint panel zone is given as

$V_{c w y}=\frac{2 h_{c w} t_{c w} \sqrt{f_{y}^{2}-\sigma_{s N}^{2}}}{\sqrt{3}}$

Bond stress is mainly generated by the friction between the column web and core concrete. The average bond strength of the CFST sections is 0.2 to $1.0 \mathrm{MPa}$ according to Zhong et al. [18]. The adhesion force $F_{\mu}$ between the column web and core concrete in the joint panel zone is calculated as

$$
F_{\mu}=V_{c c 1}=2 f_{\mu}\left(h_{c w}-2 t_{c f}\right)\left(h_{b}-t_{b f}\right)
$$

where $V_{c c l}$ is the maximum shear bearing capacity that the core concrete in the joint panel zone can provide due to the bonding stress, and $f_{\mu}$ is the bonding stress between the column web and core concrete.

Considering the confinement effect on the shear strength of the filled concrete, the ultimate shear strength of core concrete is taken as $2 f_{t}$ [19], and the ultimate shear force of the core concrete is calculated as

$V_{c c 2}=\frac{2 f_{t}\left(h_{c w}-2 t_{c f}\right)\left(b_{c f}-2 t_{c w}\right)}{\kappa}$

where $V_{c c 2}$ is the ultimate shear force that the core concrete in the joint panel can reach, $f_{t}$ is the axial tensile strength of ordinary concrete, and $\kappa$ is the nonuniformity coefficient of shear stress; it can be taken as 1.2 for a rectangular concrete cross section [13].

$$
V_{c c}=\min \left(V_{c c 1}, V_{c c 2}\right)
$$

where $V_{c c}$ is the ultimate shear force of core concrete in the joint panel zone.

The shear strain $\gamma_{A}$ and shear value $V_{A}$ at the end of the first stage (point A) are formulated as

$$
\begin{aligned}
& \gamma_{A}=\frac{\min \left(V_{c c 1}, V_{c c 2}\right)}{G_{c}\left(h_{c w}-2 t_{c f}\right)\left(b_{c f}-2 t_{c w}\right)} \\
& V_{A}=V_{c c}+\left(K_{c f}+K_{c w}\right) \gamma_{A} \\
& V_{A}=\min \left(V_{c c 1}, V_{c c 2}\right)+\left[\frac{2 E_{s}\left(b_{c f}-2 t_{c w}\right) t_{c f}^{3}}{\left(h_{b}-t_{b f}\right)^{2}}+2 G_{s} h_{c w} t_{c w}\right] \gamma_{A}
\end{aligned}
$$

Furthermore, the shear strain $\gamma_{B}$ and shear value $V_{B}$ at the end of second stage (point B) are formulated as

$$
\begin{aligned}
& \gamma_{B}=\frac{V_{c w y}}{K_{c w}}=\frac{\sqrt{f_{y}^{2}-\sigma_{s N}^{2}}}{\sqrt{3} G_{s}} \\
& V_{B}=V_{c c}+V_{c w y}+K_{c f} \gamma_{B} \\
& V_{B}=\min \left(V_{c c 1}, V_{c c 2}\right)+\frac{2 h_{c w} t_{c w} \sqrt{f_{y}^{2}-\sigma_{s N}^{2}}}{\sqrt{3}}+\frac{2 E_{s}\left(b_{c f}-2 t_{c w}\right) t_{c f}^{3} \sqrt{f_{y}^{2}-\sigma_{s N}^{2}}}{\sqrt{3} G_{s}\left(h_{b}-t_{b f}\right)^{2}}
\end{aligned}
$$

Finally, the shear strain $\gamma_{C}$ and shear value $V_{C}$ at the end of the third 
stage (point $\mathrm{C}$ ) are formulated as

$\gamma_{C}=\frac{V_{c f y}}{K_{c f}}=\frac{f_{y}\left(h_{b}-t_{b f}\right)}{3 E_{s} t_{c f}}$

$V_{C}=V_{c c}+V_{c w y}+V_{c f y}$

$V_{C}=\min \left(V_{c c 1}, V_{c c 2}\right)+\frac{2 h_{c w} t_{c w} \sqrt{f_{y}^{2}-\sigma_{s N}^{2}}}{\sqrt{3}}+\frac{2 f_{y}\left(b_{c f}-2 t_{c w}\right) t_{c f}^{2}}{3\left(h_{b}-t_{b f}\right)}$

The shear force-shear deformation mode of the panel zone of the side-plate joint can be obtained according to equations (11) to (16), as shown in Fig. 4.

\subsection{Failure-mode analysis of the side-plate joint}

Under the loading conditions, where the horizontal load plays a controlling role, the bending moment directions of the beam ends on both sides of the joint are consistent. Assuming that the beam end moment is the full-section plastic bending moment, $M_{p b}$, it can be converted into the force couple $T_{p} / C_{p}$ acting on the beam flange, as shown in Fig. 6 . The axial force of the beam flange in the side-plate joint is transmitted by the column flange, column web, and core concrete. Part of the shear force at the beam end is transmitted through the weld between the beam flange and column flange to the column flange, the remaining shear force is transmitted through the weld between beam flange and side plate to the column web and core concrete. The side-plate joint (excluding the joint panel zone) has three failure modes: (mode I) horizontal weld failure between the beam flange and side plate; (mode II) flexural failure of the side plate at the column flange position; and (mode III) significant damage or buckling at the beam beyond the side plate.

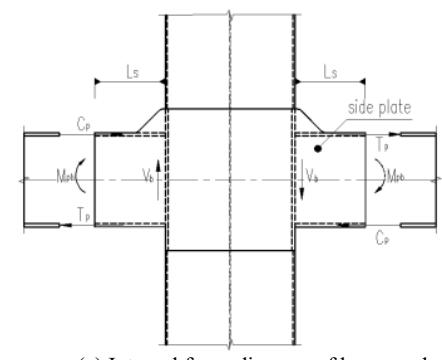

(a) Internal force diagram of beam end

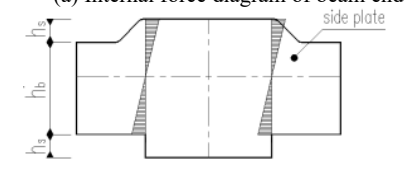

(b) Stress diagram of side plate in the column flange

Fig. 6 Internal force diagram of side-plate joint

According to equations (11) to (16), the value of the moment $M_{b f}$ transferred from the flange at the beam end is given as

$M_{b f}=\frac{V_{c f y}}{2} \times\left(h_{b}-t_{b f}\right)=f_{y}\left(b_{c f}-2 t_{c w}\right) t_{c f}^{2}$

The proportion of the bending moment transmitted by the column flange is assumed to be $\theta=M_{b f} / M_{p b}$; then, the moment transmitted by the side plate $\left(M_{b s}\right)$ is formulated as

$M_{b s}=M_{b p}-M_{b f}=(1-\theta) M_{b p}$

The horizontal strength of side plate is determined as follows:

$\frac{2 f_{y w}\left(L_{s}-2 t_{b f}\right) t_{b f}}{\sqrt{3}} \leq \frac{M_{b s}}{h_{b}-t_{b f}}=\frac{(1-\theta) M_{b p}}{h_{b}-t_{b f}}$

$F_{\mathrm{I}}=\frac{2 f_{y w}\left(L_{s}-2 t_{b f}\right) t_{b f}}{\sqrt{3}(1-\theta)} \leq \frac{M_{b p}}{h_{b}-t_{b f}}$

Further, the vertical flexural strength of the side plate is formulated as $f_{y}\left(h_{b}+h_{s}\right) t_{c w} \leq \frac{2 M_{b s}}{h_{b}+h_{s}}=\frac{2(1-\theta) M_{b p}}{h_{b}+h_{s}}$

$F_{\mathrm{II}}=\frac{f_{y}\left(h_{b}+h_{s}\right)^{2} t_{c w}}{2(1-\theta)\left(h_{b}-t_{b f}\right)} \leq \frac{M_{b p}}{h_{b}-t_{b f}}$

$F_{\mathrm{II}}=\frac{f_{y w}\left(h_{b}+h_{s}-2 t_{c w}\right)^{2} t_{c w}}{2(1-\theta)\left(h_{b}-t_{b f}\right)} \leq \frac{M_{b p}}{h_{b}-t_{b f}}$

The strength of the steel beam flange is formulated as

$F_{\mathrm{III}}=\frac{M_{b p}}{h_{b}-t_{b f}} \leq \min \left(F_{\mathrm{I}}, F_{\mathrm{II}}\right)$

where $L_{s}$ is the external length of the side plate beyond the column flange. Considering the defect at the beginning and ending of the weld, the base metal thickness will be reduced two-fold when calculating the weld length. $h_{s}$ is the height of the side plate beyond the upper beam flange, $b_{b f}$ is the width of beam flange, and $f_{y w}$ is the tensile strength of the butt weld. Equation (20b) is applicable to the joint with the column web and the side plate processed into a complete plate in the panel zone. Equation (20c) is applicable to the joint with the column web and side plate broken by the column flange and connected with the column flange through groove welding.

When $F_{\text {III }} / \min \left(F_{\mathrm{I}}, F_{\mathrm{II}}\right) \leq 100 \%$, failure mode I occurs due to damage or buckling at the beam beyond the side plate. $F_{\mathrm{II}} / F_{\mathrm{III}} \leq 100 \%$ indicates that vertical flexure strength of the side plate at the column flange is insufficient, resulting in failure mode II. $F_{\mathrm{I}} / F_{\mathrm{III}} \leq 100 \%$ indicates that the horizontal weld strength of the extended side plate is insufficient, resulting in failure mode III.

\section{Experimental study}

\subsection{Specimen design and loading system}

In order to verify the proposed equations for evaluating the joint failure modes and bearing capacity, three full-scale middle column WCFT joints were manufactured. The specimens possessed double-cavity WCFT columns and H-shaped welded composite beams. The WCFT column can meet the requirements of the stronger based on the AISC Seismic Provision recommendations [20]. The material property of steel was Q235B, and C25 grade of infill concrete was used in all specimens.

In addition to the conditions of the laboratory equipment, the column axial pressure ratio of all specimens was retained at 0.3 during the test. The axial compression ratios of the specimens were experimentally obtained as per the following relationship: $n=N /\left(f_{c m} A_{c}+f_{y m} A_{s}\right)$, where $N$ is the constant vertical load applied to the top of the column, $f_{c m}$ is the average test measurement of the axial compression strength of concrete, $A_{c}$ is the area of the infill concrete, and $A_{s}$ is the area of the steel tube.

The average values of different steel plates of the test pieces are listed in Table 1 , and the cross-sections and detailed dimensions of the specimens are listed in Table 2. A 150-mm cube (standard test block) was obtained when the infill concrete of the specimens was poured. The average compressive strength of the concrete cube measured after curing for 28 days under the same conditions as the specimens was $32.25 \mathrm{MPa}$. The modulus of elasticity of concrete was determined based on the compressive strength and $E_{c}=10^{5} /\left(2.2+34.7 / f_{c u}\right) \quad$ [17], where the shear modulus $G_{c}$ was taken as 0.4 times the elastic modulus, $E_{c}$ [21]. Fig. 7 shows the schematic of the specimen and test equipment.

Table 1

Steel properties

\begin{tabular}{cccccc}
\hline Plate specification & $f_{\mathrm{y}} / \mathrm{MPa}$ & $f_{\mathrm{u}} / \mathrm{MPa}$ & $\delta$ & $E_{s} / \mathrm{MPa}$ & $f_{\mathrm{u}} / f_{\mathrm{y}}$ \\
\hline Steel tube $(8 \mathrm{~mm})$ & 371.67 & 520.00 & $24.97 \%$ & 188667 & 1.40 \\
Steel tube $(12 \mathrm{~mm})$ & 375.00 & 493.33 & $30.59 \%$ & 217000 & 1.32 \\
Beam flange & 383.33 & 535.00 & $30.18 \%$ & 210667 & 1.40 \\
Beam web & 380.40 & 513.70 & $24.67 \%$ & 175700 & 1.35 \\
\hline
\end{tabular}

$\delta$ is the steel elongation. 
Table 2

Section size of test specimens

\begin{tabular}{|c|c|c|c|c|c|c|}
\hline $\begin{array}{l}\text { Specimen } \\
\text { number }\end{array}$ & $\begin{array}{l}\text { WCFT } \\
\text { column } / \mathrm{mm}\end{array}$ & H-shaped beam/mm & $\begin{array}{l}\text { Column web in panel } \\
\text { zone } / \mathrm{mm}\end{array}$ & $\begin{array}{c}\text { Column flange in panel } \\
\text { zone } / \mathrm{mm}\end{array}$ & $\begin{array}{l}\text { Extension length of side } \\
\text { plate } / \mathrm{mm}\end{array}$ & Column height $/ \mathrm{mm}$ \\
\hline JD-1 & $550 \times 180 \times 8$ & $\mathrm{H} 400 \times 180 \times 8 \times 14$ & $550 \times 600 \times 12$ & $156 \times 600 \times 12$ & $300 \times 500 \times 12$ & 2900 \\
\hline JD-2 & $550 \times 180 \times 8$ & $\mathrm{H} 400 \times 180 \times 8 \times 14$ & $526 \times 600 \times 12$ & $180 \times 600 \times 12$ & $300 \times 500 \times 12$ & 2900 \\
\hline $\mathrm{JD}-3$ & $550 \times 180 \times 8$ & $\mathrm{H} 400 \times 180 \times 8 \times 14$ & $550 \times 600 \times 12$ & $156 \times 600 \times 12$ & $240 \times 500 \times 12$ & 2900 \\
\hline
\end{tabular}

1. The joint configuration of the JD-1 specimen implies that the column web in the panel zone and extended side plate are processed into a complete plate; the column web and side plate of the JD-2 specimen are separate and connected to the column flange through groove welding. 2 . The column height is the distance from the top of the column to the center of the bottom pin shaft.

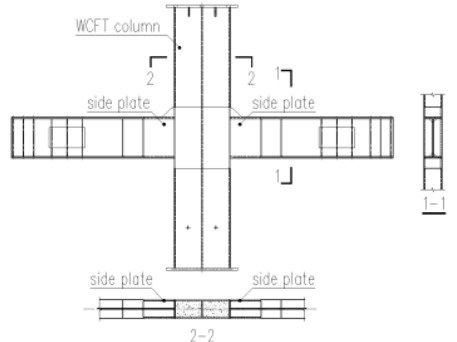

(a) Schematic of specimen

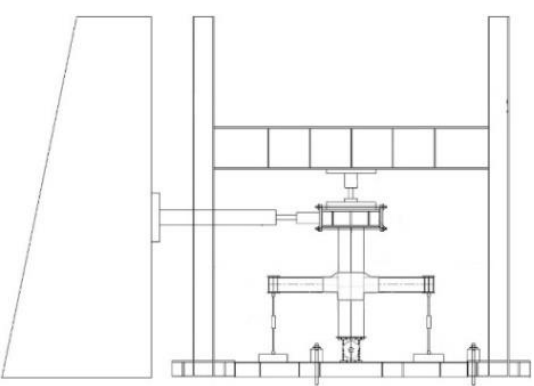

(b) Schematic of test equipment

Fig. 7 Schematic of test specimens and test equipment

During the specimen-loading process, a predetermined constant vertical load was first applied to the top of the column, followed by a low-period horizontal cyclic load. The horizontal loading scheme followed the loaddisplacement hybrid method [22], i.e., the load control and displacement control before and after the yield of specimens, respectively. In the displacement control, a same displacement is repeated three times at each load stage until the test specimen is broken. The test specimen loading scheme is shown in Fig. 8.

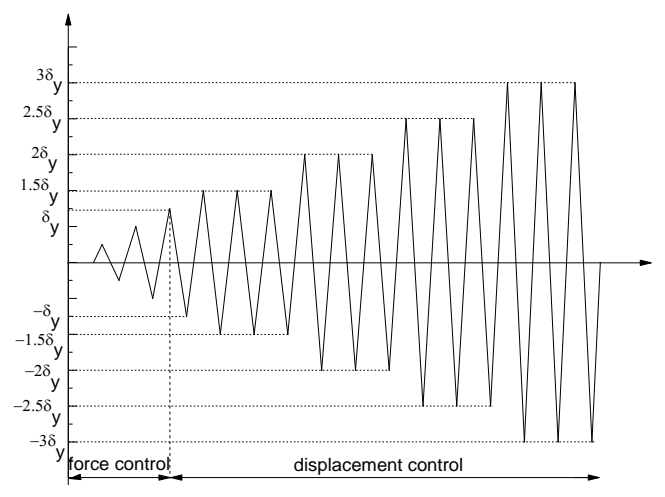

Fig. 8 Schematic of loading system

\subsection{Test phenomenon and failure mode}

As the JD-1 specimen loading reached a reciprocating load of $36 \mathrm{~mm}$, the strain-data acquisition box showed that the steel beam flange had reached the yield strain at many points, and the load-displacement curve showed a slight inflection point, indicating that the JD- 1 specimen had entered plasticity at this moment. When a reciprocating load of $2.5 \delta_{y}(90 \mathrm{~mm})$ was applied on the JD-1 specimen, the web of the east beam slightly deformed and buckled; furthermore, during the reciprocating load of $3.5 \delta_{\mathrm{y}}$, the upper and lower flanges of the steel beam outside the east side appeared to buckle, and the web bulging was evident. During first round of application of a reciprocating load of $4 \delta_{\mathrm{y}}(144 \mathrm{~mm})$ on the JD-1 specimen, the beam web and flanges on both sides of the column buckled, and the bearing capacity decreased by 0.8 times the ultimate bearing capacity. At this moment, the test was stopped; the failure mode of the JD-1 specimen is shown in Fig. 9. Owing to the existence of the side plate at the beam end, the position of the plastic hinge of JD-1 was shifted from the panel zone; this effectively protected the panel zone of the joint. A plastic hinge was formed at approximately 0.8 to 1.0 times the beam height from the column flange that effectively protected the panel zone of the joint.

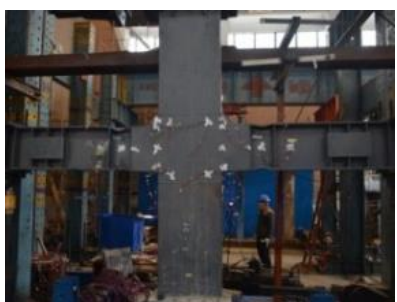

(a) Final failure state

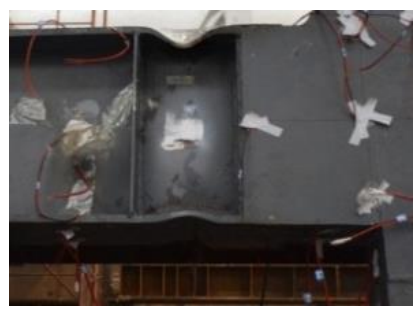

(b) Buckling of flange
Fig. 9 Final failure mode of JD-1 (mode I)

As the JD-2 specimen loading reached a reciprocating load of $40 \mathrm{~mm}$, a slight inflection point appeared in the load-displacement curve, and the JD-2 specimen was observed to enter the plastic state. During the test cycle of $1.5 \delta_{y}$ $(60 \mathrm{~mm})$, when the first circle was pulled to $60 \mathrm{~mm}$, no obvious deformation phenomenon was observed on the flange and web of the beam; however, the weld at the joint between the lower flange of the southwest beam and column flange cracked. As the second circle was pushed to $60 \mathrm{~mm}$, the weld connecting the column flange and southeast-side plate cracked, and the crack developed rapidly to $15 \mathrm{~cm}$. The test was stopped at this time; the test failure mode of the JD-2 test piece is shown in Fig. 10.

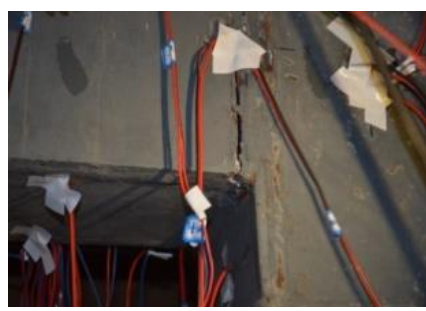

Fig. 10 Final failure mode of JD-2 (mode II)

As the JD-3 specimen loading reached the yield load, a reciprocating load of $36 \mathrm{~mm}$ was applied on it. During the test cycle of $1.5 \delta_{\mathrm{y}}(54 \mathrm{~mm})$, no obvious deformation phenomenon occurred in the column and side plate; however, the weld at the joint connecting the lower flange of the southwest beam and upper flange of the northeast beam with the side plate cracked, and the crack quickly developed. Furthermore, the horizontal load at the top of the column could not be maintained, and the test was stopped. The test failure mode of the JD-3 specimen is shown in Fig. 11. 


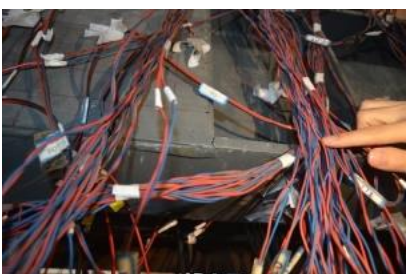

(a) Cracking on the east-side beam

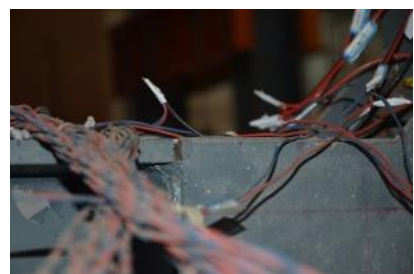

(b) Cracking on the west-side beam
Fig. 11 Final failure mode of JD-3 (mode III)

After all specimens were tested, the core web and column flange plates were cut open. The integrity of the core concrete in the panel zone of all specimens was good, and no horizontal or oblique cracks were visible on the surface, as shown in Fig. 12.

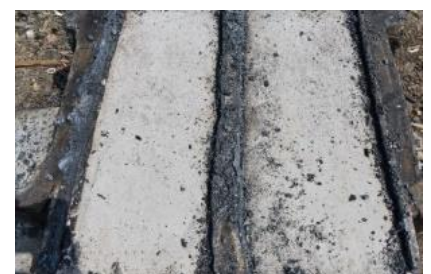

(a) Column flange side

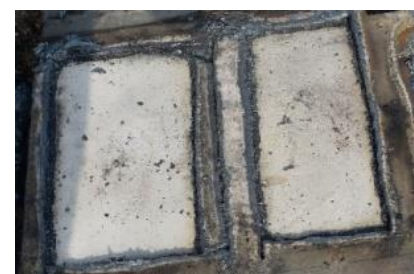

(b) Column web side
Fig. 12 Final status of core concrete

\section{Test results and analysis}

\subsection{Hysteresis curve}

The hysteresis curve can reflect many indexes of the seismic performance of the joint. By monitoring the displacement and load at the top of the column during the test, the load-displacement hysteresis curves of the three specimens were obtained, as shown in Fig. 13.

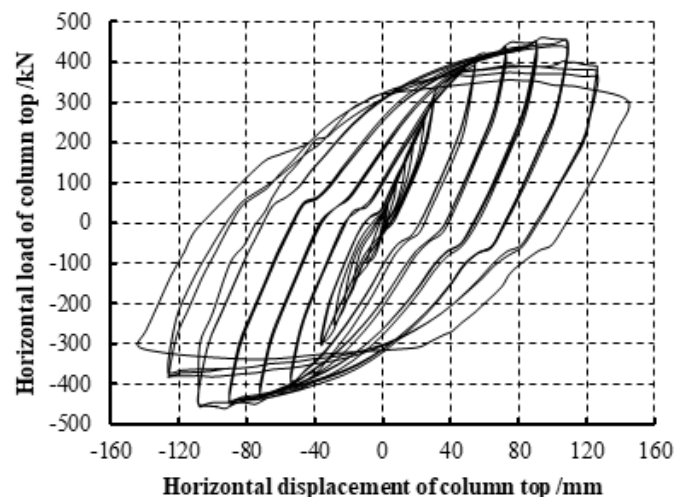

(a) Hysteresis curve of JD-1

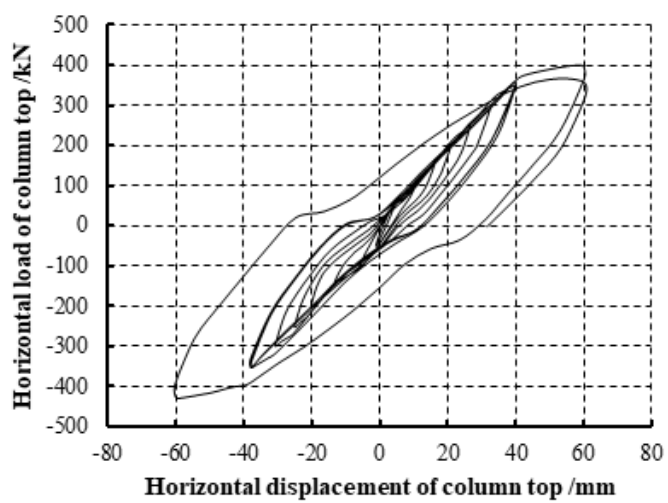

(b) Hysteresis curve of JD-2



(c) Hysteresis curve of JD-3

Fig. 13 Cyclic lateral load versus lateral displacement hysteresis curve

1) Before the specimens enter the yield state, the area of all the hysteresis loops are small, and the shape of the hysteresis curve is a sharp shuttle. After the JD-1 specimen yields, the hysteresis loop area expands continuously with the increase of plastic deformation. The steel beam gradually enters plasticity to form a plastic hinge. Under ultimate load, the whole hysteresis loop is full and shuttle-shaped without any evident pinching phenomenon.

2) Compared with JD-1 and JD-3, the shape of the hysteresis curve of the JD-2 specimen in the elastic stage is similar to that of the JD-1 specimen, and it shows a sharp shuttle shape. In the first cycle of the displacement loading stage, cracks appeared in the weld between the side plate and column flange, resulting in a break in the hysteresis curve. The hysteresis curve of the JD-2 specimen reflects the joint configuration has less plastic deformation ability.

3) In the JD-1 and JD-3 specimens, the column web in the panel zone and the extended side plate are processed into one complete plate. The difference is that the length of extended side plate of JD-3 is $80 \%$ that of JD- 1 . The hysteresis curves of these specimens before yielding are coincident. During the first cycle of the displacement loading stage, the weld between the tensile flange at the end of the JD-3 test specimen and the extended side plate cracks, resulting in an interruption in the hysteresis curve without the formation of a closed hysteresis loop after yield.

\subsection{Skeleton curve}

Fig. 14 shows the horizontal load-displacement skeleton curves of the specimens at the top of the column. The "universal bending-yield method" was adopted to determine yield load $P_{y}$ and yield displacement $\Delta_{y}$ [23]. The corresponding displacement when the skeleton curve load drops to $85 \%$ of peak load $P_{p}$ is considered the ultimate displacement, $\triangle_{u}$ [26]. The story drift ratio $\theta_{u}$ is defined as the ratio of horizontal limit displacement $\Delta_{u}$ to the column height. During the loading process, the difference between the loads in the two directions, i.e., push and pull, is small. The displacement and load at the characteristic point were obtained from the average value of both loads. The displacements, loads, and story drift ratio at the characteristic points of the three specimens are shown in Table 3.

According to Fig. 14 and Table 3, the following results can be derived.

1) The growth of the skeleton curves of all joint specimens are similar at the early stage, and the slopes of the skeleton curves of all three specimens at this stage are very close; this shows that the extended length of the side plate have a small effect on the initial stiffness of the side plate joint.

2) The ultimate loads of the JD-2 and JD-3 specimens are larger than the yield loads of the JD-1 specimen; i.e., $91.3 \%$ and $96.4 \%$ of the ultimate loads of the JD-1 specimen, respectively. This indicates that the JD-2 and JD-3 specimens also enter the yield stage of the joints, while the strain-hardening potential of steel material is not effectively developed.

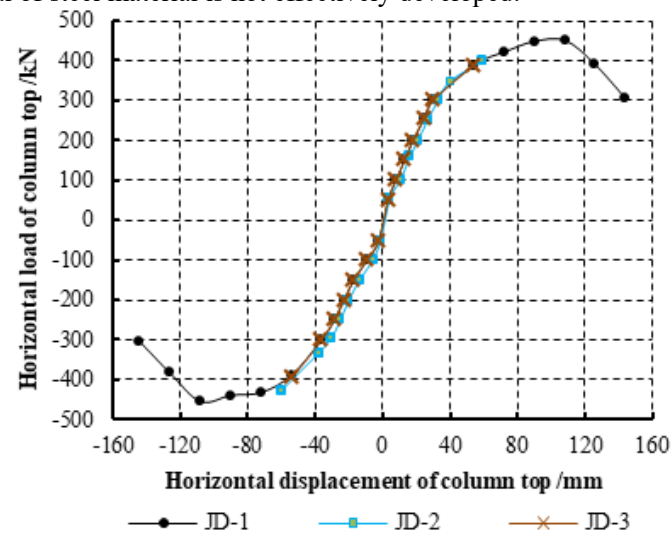

Fig. 14 Skeleton curves of specimens 
Table 3

Main test results

\begin{tabular}{cccccc}
\hline Specimen number & $P_{y} / \mathrm{kN}$ & $\Delta_{y} / \mathrm{mm}$ & $P_{p} / \mathrm{kN}$ & $\Delta_{u} / \mathrm{mm}$ & $\theta_{u} / \mathrm{rad}$ \\
\hline JD-1 & 369.10 & 44.02 & 452.60 & 132.73 & 0.045 \\
JD-2 & $/$ & $/$ & 413.19 & 59.71 & 0.020 \\
JD-3 & $/$ & $/$ & 391.05 & 53.67 & 0.018
\end{tabular}

The JD-2 and JD-3 specimens reached their failure modes shortly after they entered plasticity, and the yield load could not be determined according to the universal bending yield method. The values of $P_{p}, \Delta_{u}$, and $\theta_{u}$ were obtained from the end point data of the skeleton curve.

\subsection{Shear and strain in the joint panel zone}

To study the stress distribution in the joint panel zone, the strains at the center points of the column webs of the three test pieces were extracted. The strains of the JD-2 and JD-3 specimens were similar to the early stage of the JD-1 specimen. Fig. 15 shows the relation between the shear strain at the center point of the web in the panel zone and horizon load at the column top of the JD-1 specimen. The maximum strain value of the center point of the web was $2.32 \times 10^{-3}$, which did not reach the shear yield strain of the specimen web. The concrete in the joint panel zone of the specimen, as presented in Fig. 12, did not show cracks or crushing. This indicates that when the ultimate load of the specimen was reached, the panel zone was still in the elastic stage without shear failure, which is suitable for a ductile moment frame [24, 25].



Fig. 15 Shear strain curve of JD-1 column web versus lateral load

The horizontal shear forces and shear deformation of the joint panel zone at the yield points of the JD-1 specimen calculated from equations (5) to (16) are presented in Table 4. Under the ultimate load, the maximum shear strain of the web was between $\gamma_{A}$ and $\gamma_{B}$. This shows that the panel zone is at the second stage of the shearing model, as shown in Fig. 4. By substituting the shear strain of the web recorded by the strain gauge into equations (5) to (16) and by using Fig. 4, the maximum shear force value $V_{n l}$ of the panel zone was found to be $2709 \mathrm{kN}$. Then, based on the principle of static equilibrium, the ultimate horizontal shear force $V_{n 2}$ of the panel zone was calculated as $2948 \mathrm{kN}$, by substituting the ultimate load of the column in the test into equations (2) to (4).

The maximum horizontal shear force $V_{n l}$ in the joint panel zone obtained by equations (5) to (16) and Fig. 4 was $91.9 \%$ of $V_{n 2}$ by the principle of static equilibrium. This may be because equations $(10 \mathrm{a})$ to $(10 \mathrm{c})$ underestimate the shear contribution of core concrete in the specimen.

\section{Table 4}

Turning point parameters of the shear model in the panel zone

\begin{tabular}{ccccc}
\hline Specimen number & $V_{c c l} / \mathrm{kN}$ & $V_{c c 2} / \mathrm{kN}$ & $V_{A} / \mathrm{kN}$ & $\gamma_{A}\left(10^{-4}\right)$ \\
\hline JD-1 & 81 to 406 & 286 & 81.2 to 286 & 0.8 to 2.8 \\
\hline \hline Specimen number & $\gamma_{B}\left(10^{-4}\right)$ & $V_{B} / \mathrm{kN}$ & $\gamma_{C}\left(10^{-4}\right)$ & $V_{C} / \mathrm{kN}$ \\
\hline JD-1 & 27.2 & 2924 to 3129 & 204.5 & 2937 to 3142 \\
\hline
\end{tabular}

\subsection{Deformation capacity and energy-consumption performance}

The AISC Seismic Provision [20] recommends that the story shift angle of the beam-column joints in the special moment frames should not be less than $0.04 \mathrm{rad}$. According to the data in Table 3, the story shift angle corresponding to the ultimate displacement of JD-1 is $0.045 \mathrm{rad}$, which exceeds the specified limit value.
In this study, the displacement ductility coefficient $\Delta_{u} / \triangle_{y}$ was adopted as an important index to measure the deformation ability of the specimens [27]. The JD-2 and JD-3 specimens were damaged quickly and lost their ability to continue to bear load after they entered the plastic phase, thus showing the characteristics of brittle failure. According to the data in Table 5, the displacement ductility coefficients of the JD-1 specimen were 3.02 and 3.01 in two loading directions. This indicates that the reasonably designed side-plate joint specimen has preferable ductility.

The equivalent viscous damping coefficient, $h_{e}$, was adopted to evaluate the energy dissipation capacity of the joint specimen [28]. Fig. 16 shows the equivalent viscous damping coefficient curve of the JD-1 specimen. According to Fig. 16, the equivalent viscosity coefficient, $h_{e}$, gradually increases with the increase in the cyclic loading level. At the time of specimen failure, the $h_{e}$ of the JD-1 specimen was 0.47 , indicating that the specimen has a large energy-consumption capacity.

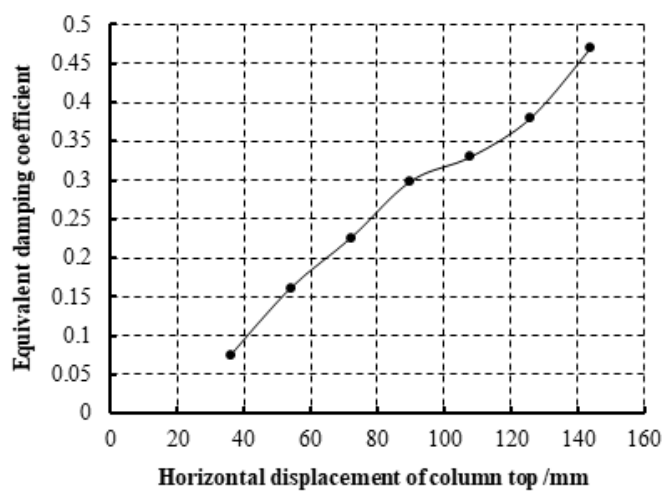

Fig. 16 Equivalent viscous damping coefficient

Table 5

Ductility factor of the JD-1 specimen

\begin{tabular}{ccccc}
\hline $\begin{array}{c}\text { Specimen } \\
\text { number }\end{array}$ & $\begin{array}{c}\text { Loading } \\
\text { direction }\end{array}$ & $\begin{array}{c}\text { Yield } \\
\text { displacement } / \mathrm{mm}\end{array}$ & $\begin{array}{c}\text { Ultimate } \\
\text { displacement } / \mathrm{mm}\end{array}$ & $\begin{array}{c}\text { Ductility } \\
\text { coefficient }\end{array}$ \\
\hline \multirow{2}{*}{ JD-1 } & + & 43.73 & 108.21 & 3.02 \\
& - & 44.32 & 108.13 & 3.01 \\
\hline
\end{tabular}

\subsection{Stiffness degradation}

To further study the change pattern of the load-displacement curve of the side-plate joint, the peak stiffness $K_{i}$, calculated using equation (22), was adopted to analyze the stiffness degradation of the structure under the influence of cumulative damage. The degradation curve of the peak stiffness for each cycle stage of the JD-1 specimen is shown in Fig. 17, where the horizontal axis is the displacement of each cycle's loading stage, and the vertical axis represents $K_{i} / K_{0}$, where $K_{0}$ is the initial stiffness of the specimen. As shown in Fig. 17, the stiffness degradation of the JD-1 specimen is relatively uniform and gentle, and no obvious sharp drops are evident in the stiffness; this indicates that the energy-consumption capacity of the JD-1 specimen is relatively stable.

$$
K_{i}=\frac{\left|-F_{\mathrm{i}}\right|+\left|+F_{i}\right|}{\left|-X_{i}\right|+\left|+X_{i}\right|}
$$

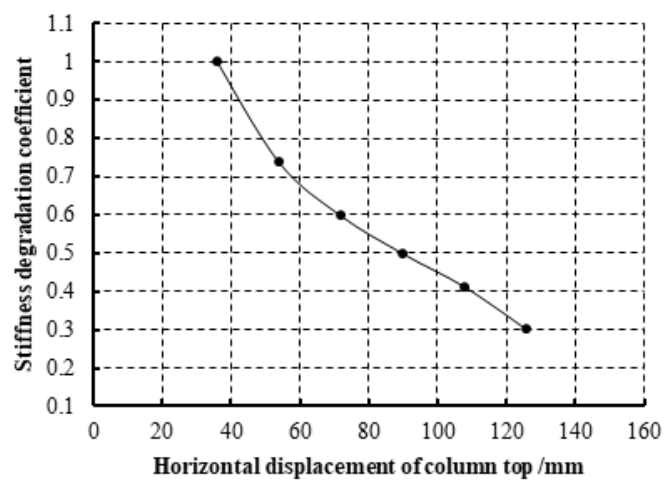

Fig. 17 Stiffness degradation coefficient 


\subsection{Verification of the ultimate bearing capacity calculation method}

Table 6 lists the strength ratios and predicted failure modes of the three specimens according to the theoretical formulae in (18) to (21). A comparison among the test phenomena of the three specimens shows that the predicted failure modes agree well with those obtained in the tests, as shown in Table 6 . In addition, when the bending moment at the end of the steel beam reached the full-section plastic moment, $M_{b p}$, the theoretical ultimate load of the three joints was calculated according to equation (2) as $457.42 \mathrm{kN}$. Table 7 shows the ultimate load of the three specimens. The ultimate load of the JD-1 specimen is very similar to its theoretical value, showing that the plastic hinge is formed at the beam end of the specimen. As shown, the theoretically calculated strength ratios in Table 6 are in good agreement with the ultimate load ratios obtained from three specimens listed in Table 7.

\section{Table 6}

Strength ratio of specimens and expected failure mode

\begin{tabular}{cccc}
\hline Specimen number & $F_{\mathrm{I}} / F_{\mathrm{III}}(\%)$ & $F_{\mathrm{II}} / F_{\mathrm{III}}(\%)$ & Predicted failure mode \\
\hline JD-1 & 110 & 121 & Mode I \\
JD-2 & 110 & 88 & Mode II \\
JD-3 & 85 & 121 & Mode III \\
\hline
\end{tabular}

\section{Table 7}

Ultimate load index at the top of column

\begin{tabular}{ccccccc}
\hline Specimen number & \multicolumn{2}{c}{ JD-1 } & \multicolumn{2}{c}{ JD-2 } & \multicolumn{2}{c}{ JD-3 } \\
\hline Loading direction & + & - & + & - & + & - \\
Ultimate load $/ \mathrm{kN}$ & 461.2 & -460.6 & 429.0 & -399.9 & 389.1 & -393.0 \\
Ratio (\%) & 100.8 & 100.7 & 93.8 & 87.4 & 85.1 & 85.9 \\
\hline
\end{tabular}

The ratio is the ultimate load of the specimens divided by the theoretically calculated ultimate load.

\section{Conclusions}

This paper presented a new side-plate column-beam joint for WCFT columns. The force-transfer mechanism and failure mode of the joint were theoretically studied. Three full-scale joints were tested to demonstrate the reliability of the proposed design method for different failure modes. Additionally, the mechanical properties of the joints were experimentally analyzed. The following conclusions were obtained.

1) Based on the analysis of the deformation characteristics of the panel zone of the side-plate joint of the WCFT column, the shear mechanisms of the joint was simplified as a three-stage model, which could be used to describe the force-deformation relation of the panel zone under shear.

2) The paper proposes three failure modes for the side-plate joints by examining the transfer mechanism of the internal force at the beam end. Mode I failure occurs due to the plastic hinge at the beam end beyond the side plate; mode II indicates the flexure failure of the side plate that occurs at the column flange; and mode III is the horizontal weld failure that occurs between the beam flange and side plate. The corresponding formulas of these failure modes are derived in this paper.

3) Three full-scale specimens of the WCFT column side-plate joint were designed for experimental demonstration. The theoretical failure modes and the predicted ultimate load were found to be in good agreement with the test results.

4) In the JD-1 specimen, where failure mode I occurred, typical beam end plastic hinges were formed at the section located 0.8 to 1.0 times the beam height from the column flange. The panel zone was in the elastic stage, the displacement ductility coefficient was more than 3 , the elastic-plastic story displacement shift angle was $0.045 \mathrm{rad}$, and the equivalent viscous damping coefficient was 0.47 . Thus, the joint specimen with failure mode I showed good deformation ability and energy dissipation performance.

5) Moreover, the joint specimens with failure modes II and III failed under the first-stage cyclic displacement load after yielding. In addition, plastic deformation did not occur, and the cumulative area of the hysteresis loop was small. Thus, the specimens with failure modes II and III presented the characteristics of brittle failure. During the design process, it should be ensured that both $\mathrm{F}_{\mathrm{I}} / \mathrm{F}_{\mathrm{III}}$ and $\mathrm{F}_{\mathrm{II}} / \mathrm{F}_{\mathrm{III}}$ are greater than $100 \%$ to avoid the brittle failure of modes II and III, thereby forming a plastic hinge at the beam end.

6) Based on the comprehensive analysis of the failure modes, hysteresis curve, skeleton curve, deformation capacity, and energy dissipation capacity of the side plate joints, the innovative joint that is used to connect a WCFT column and steel beam can achieve an ideal seismic performance through reasonable design.

\section{References}

[1] Nakashima, M., Roeder C.W. and Maruoka. Y., "Steel Moment Frames for Earthquakes in United States and Japan", Journal of Structural Engineering, 126(8), 861-868, 2000.

[2] Sherman, D.R., "Designing with Structural Tubing", Engineering Journal, 33(3), 101-109, 1996.

[3] Mirghaderi, S.R., Torabian, S. and Keshavarzi, F., "I-beam to Box-column Connection by a Vertical Plate Passing through the Column”, Engineering Structures, 32(8), 2034-2048, 2010.

[4] GB 50936-2014 Technical Code for Concrete Filled Steel Tubular Structures, China Architecture \& Building Press, Beijing, China, 2014. (in Chinese)

[5] Hao, J.P., Sun, X.L., Xue, Q. and Fan, C.L., "Research and Application of Fabricated Steel Structure Building System", Engineering Mechanics, 34(1), 1-13, 2017. (in Chinese)

[6] Sun, X.L., Hao, J.P., Xue, Q., Fan, C.L., Liu, H. and He, M.N., "Experimental Study on Seismic Behavior of Walled Concrete-filled Steel Tubular Columns", Journal of Building Structures, 39(6), pp. 92-101, 2018. (in Chinese)

[7] Sasaki, S., Teraoka, M. and Fujiwara, T., "Structural Behavior of Concrete-filled Square Column with Partial-penetration Weld corner Seam to Steel H-beam Connections", Pergamon Press, Singapore, 2, 33-40, 1995

[8] Shim, J.S., Han, D.J. and Kim, K.S., "An Experimental Study on the Structural Behaviors of H-shaped Steel Beam-to-concrete Filled Steel Square Tubular Column Connections", Pergamon Press, Singapore, 2, 41-48, 1995.

[9] Lu, X.L., Yu, Y., Kiyoshi, T. and Satoshi, S., "Experimental Study on the Seismic Behavior in the Connection Between CFRT Column and Steel Beam", Structural Engineering and Mechanics, 9(4), 365-374, 2000.

[10] Cheng, C.T. and Chung, L.L., "Seismic Performance of Steel Beams to Concrete-filled Steel Tubular Column Connections", Journal of Constructional Steel Research, 59(3), 405-426, 2003

[11] Fukumoto, T. and Morita, K., "Elasto-plastic Behavior of Panel Zone in Steel Beam-to-concrete Filled Steel Tube Column Moment Connections", Journal of Structural Engineering, 131(12), 1841-1853, 2005.

[12] Furlong, R.W., "Design of Steel-encased Concrete Beam-column", Journal of Structural Division, 94(ST1), 267-281, 1968.

[13] Park, R. and Paulay, T., "Reinforced Concrete Structures", Chongqing University Press, Chongqing, China, 1985. (in Chinese))

[14] Paulay, T. and Priestley, M.J.N., "Seismic Design of Reinforced Concrete and Masonry Buildings", China Architecture \& Building Press, Beijing, China, 1999. (in Chinese)

[15] Morishita, Y., Tomii, M. and Yoshimura, K., "Experimental Studies on Bond Strength in Concrete Filled Square and Octagonal Steel Tubular Columns Subjected to Axial Loads", Transactions of Japan Concrete Institute, 1, 359-366, 1979.

[16] Morishita, Y., Tomii, M., "Experimental Studies on Bond Strength between Square Steel Tube and Encased Concrete Core under Cyclic Shearing Force and Constant Axial Force", Transactions of Japan Concrete Institute, 4, 363-370, 1982

[17] Xu, L.H., Fan, H. and Li, Q.S., "Experimental Studies on Seismic Behavior of Connection between Concrete-filled Steel Square Tubular Column and Steel Beam", Engineering Mechanics, 25(2), 122-131, 2008. (in Chinese)

[18] Zhong, T., T.Y. Song, Brian Uy. and Han, L.H., "Bond Behavior in Concrete-filled Steel Tubes", Journal of Constructional Steel Research, 120, 81-93, 2016.

[19] Xiao, C.Z., Cai, S.H. and Xu C.L., "Experimental Study on Shear Performance of Concrete Filled Steel Tube Columns", China Civil Engineering Journal, 4, 5-11, 2005. (in Chinese)

[20] ANSI/AISC 341-16 Seismic Provisions for Structural Steel Buildings, American Institute of Steel Construction, Chicago (IL), 2016.

[21] Zia, P. "Torsional strength of prestressed concrete members", Journal Proceedings, 57(4), $1337-1360,1961$

[22] JGJ101-96 Specification of Testing Methods for Earthquake Resistant building, China Architecture \& Building Press, Beijing, China, 1997. (in Chinese)

[23] Wang, W.D., Han, L.H., Uy B., "Experimental Behaviour of Steel Reduced Beam Section to Concrete-filled Circular Hollow Section Column Connections", Journal of Constructional Steel Research, 64(5), 493-504, 2008.

[24] FEMA-355D State of the Art Report on Connection Performance, Federal Emergency Management Agency, Washington (DC), 2000

[25] Roeder, C.W., "General Issues Influencing Connection Performance", Journal of Structural Engineering, 128(4), 420-428, 2002.

[26] Chen, J., Chan, T.M., Su, R.K.L. and Castro, J.M., "Experimental Assessment of the Cyclic Behaviour of Concrete-filled Steel Tubular Beam-columns with Octagonal Sections", Engineering Structures, 180, 544-560, 2019.

[27] EN 12390-3:2009 Testing Hardened Concrete. Part 3: Compressive Strength of Test Specimens, CEN (European Committee for Standardization), 2009.

[28] Wang, Y.H., Lu, G.B. and Zhou, X. H., "Experimental Study of the Cyclic Behavior of Concrete-filled Double Skin Steel Tube Columns Subjected to Pure Torsion”, Thin-Walled Structures, 122, 425-438, 2018 